Running head: Psychosocial issues and physical activity to prevent falls

\title{
Psychosocial issues in Engaging Older People with Physical Activity Interventions for the Prevention of Falls
}

\author{
Dr Samuel R. Nyman, PhD \\ School of Design, Engineering \& Computing, \\ Bournemouth University, \\ Poole House, Talbot Campus, Poole, Dorset, BH12 5BB, UK.
}

Tel: +44 (0)1202 968179, Fax: +44 (0)1202 965314. snyman@ bournemouth.ac.uk

Nyman, S. (2011). Psychosocial issues in engaging older people with physical activity interventions for the prevention of falls. Canadian Journal on Aging, 30(1), 45-55. 


\section{ABSTRACT}

This paper presents an overview of the psychosocial factors that influence older people's participation in physical activity interventions for the prevention of falls. The importance of psychosocial factors is stressed as interventions will be rendered useless if they do not successfully gain the active participation of older people. The theory of planned behaviour (Ajzen, 1988) is used as a framework for the review on how knowledge (a prerequisite), attitudes, subjective norm (the social context), and perceived behavioural control (confidence) promotes or inhibits intention to carry out activities to prevent falls. The review is supplemented with evidence for self-identity to influence intention, and the paper concludes with a discussion of the recommendations made by the Prevention of Falls Network Europe for engaging older people in falls prevention.

\section{RESUMÉ}

Dans cet article on présente une vue d'ensemble des facteurs psychosociaux ayant une influence sur la participation des personnes âgées aux interventions concernant l'activité physique et visant la prévention des chutes. On met l'accent sur l'importance des facteurs psychosociaux puisque les interventions seront rendues inutiles si elles ne réussisent pas à attirer la participation active des personnes âgées. La théorie du comportement planifié (Ajzen, 1988) sert de cadre à un passage en revue de la façon dont les connaissances (un préalable), les attitudes, les normes subjectives, (le contexte social) et la perception du contrôle comportemental (la confiance) encouragent ou entravent l'intention d'entreprendre des activités pour la prévention des chutes. Cette étude est accompagnée de documents qui indiquent la manière dont la perception de soi influence l'intention,.L'article se termine par une Nyman, S. (2011). Psychosocial issues in engaging older people with physical activity interventions for the prevention of falls. Canadian Journal on Aging, 30(1), 45-55. 
discussion des recommendations faites par le réseau européen ProFaNE (Prevention of Falls Network Europe) en ce qui concerne l'implication des personnes âgées dans la prévention des chutes.

Key words: adherence, falls, physical activity, prevention, psychosocial, review

Word count of main body of text: 4942

Nyman, S. (2011). Psychosocial issues in engaging older people with physical activity interventions for the prevention of falls. Canadian Journal on Aging, 30(1), 45-55. 


\section{Introduction}

The recent Cochrane systematic review of interventions with community-dwelling older people found that falls are prevented by regular exercise and Tai Chi, and in some cases multifactorial risk assessment and intervention, home hazard reduction, vitamin D supplementation, and gradual withdrawal of excessive / balance impairing medications (Gillespie et al., 2009). Yet, interventions for the prevention of falls require older people's participation, and so an understanding of psychosocial factors that influence people's engagement is required. Psychosocial models can be used to understand why older people may not wish to engage in falls prevention interventions and predict under what conditions an older person would be more likely to participate.

Even the most well-crafted falls prevention interventions will be rendered useless if older people decline to participate in them (Dracup \& Meleis, 1982; Yardley et al., 2006a; Yardley, Donovan-Hall, Francis, \& Todd, 2007b), and it is not unknown for health interventions to fail because the target group has not accessed the service (Stoop, van't Riet, \& Berg, 2004). Non-participation in interventions is costly in terms of both wasted resources and the treatment of those who have not adhered to the programme (Kyngas, Duffy, \& Kroll, 2000). Some falls prevention interventions have as many as a third of older people declining participation (Shekelle et al., 2003) and a response rate as low as 10\% (Day et al., 2002). Adherence rates also range from as high as $84 \%$ to as low as $44 \%$ at two years post-baseline (Campbell, Robertson, Gardner, Norton, \& Buchner, 1999; Day et al., 2002; Shekelle et al., 2003).

Therefore, this paper presents an overview of the various psychosocial factors that act as barriers and facilitators to older people's engagement in falls prevention

Nyman, S. (2011). Psychosocial issues in engaging older people with physical activity interventions for the prevention of falls. Canadian Journal on Aging, 30(1), 45-55. 
interventions. While the findings summarised in this review may be relevant to other falls prevention interventions, the focus of this review is on interventions that seek to prevent falls by increasing older people's physical activity. Focusing on physical activity interventions is warranted because these interventions have the strongest evidence-base for preventing falls (Gillespie et al., 2009), and because they rely more on older people's active engagement than other interventions such as taking medications (Chao, Foy, \& Farmer, 2000).

Because of the number of psychosocial factors that influence engagement with falls prevention interventions (Bunn, Dickinson, Barnett-Page, McInnes, \& Horton, 2008), the use of health psychology theory will be useful in synthesising this literature. There are a number of psychosocial models used to predict health behaviours, most of which fall under the banner of social cognition models. Social cognition models are theories that assume people make reasoned decisions about engaging in health behaviours and do so whilst influenced by social and environmental factors (Ogden, 2000). Whilst a number of social cognition models could be applied to the study of increasing older people's uptake and adherence to falls prevention interventions, the theory of planned behaviour is an extensively used and validated model in health psychology and has already been used in falls prevention research, and so is used to frame the literature in this review.

In the sections that follow, psychosocial factors that explain older people's participation in physical activity interventions for the prevention of falls are reviewed under the framework of the theory of planned behaviour: knowledge, attitude toward the behaviour, subjective norm, perceived behavioural control, and intention. Among Nyman, S. (2011). Psychosocial issues in engaging older people with physical activity interventions for the prevention of falls. Canadian Journal on Aging, 30(1), 45-55. 
the variables that have been proposed as additional constructs to the theory of planned behaviour to strengthen its power to predict intention to engage in a given behaviour (Conner \& Armitage, 1998), self-identity has been found to be pertinent to falls prevention and so is included in this review. Lastly, reference is made to the recommendations made by the Prevention of Falls Network Europe for promoting older people's engagement in falls prevention interventions. Before reviewing the literature on falls prevention the theory of planned behaviour is described below.

\section{The Theory of Planned Behaviour}

The theory of planned behaviour (TPB) (Ajzen, 1988) asserts that behaviour change is exercised through intention: "Intentions are assumed to capture the motivational factors that influence a behavior; they are indications of how hard people are willing to try, of how much an effort they are planning to exert, in order to perform the behaviour" (Ajzen, 1991, p. 181). As presented in Figure 1, the TPB model asserts that intention is predicted by three variables: attitude toward the behaviour, subjective norm, and perceived behavioural control.

Attitude toward the behaviour is the positive / negative evaluation of carrying out a behaviour and its consequences, as well as the likelihood of these outcomes occurring (behavioural beliefs). Subjective norm is the anticipated social pressure from significant others (e.g. spouse, relative, close friend, doctor, carer, etc.) to carry out a particular behaviour (normative beliefs), and degree of motivation to adhere to such pressure. Perceived behavioural control (PBC) is the level of self-efficacy / confidence a person has in whether or not they will be able to carry out a particular

Nyman, S. (2011). Psychosocial issues in engaging older people with physical activity interventions for the prevention of falls. Canadian Journal on Aging, 30(1), 45-55. 
behaviour, given the perceived presence of factors that may facilitate or hinder their performance (control beliefs) (Ajzen, 2006).

Figure 1 also indicates that behaviour can be predicted by perceived behavioural control directly, especially when perceived control closely matches actual control. Indeed, a person may have strong intentions to carry out a behaviour but feels unable (low perceived behavioural control) to follow through with these intentions (Ajzen, 1988). Thus, actual behavioural control - whether a person has the skills, resources, etc. - is acknowledged in the model to note that perceived and actual behavioural control may not match, but when they do perceived behavioural control can act as a proxy for actual behavioural control (Ajzen, 2006).

The TPB model has successfully predicted behaviour with a medium to large effect size and explained $19-38 \%$ of the variance in e.g. undertaking exercise, smoking cessation, condom use, and pro-environmental choices, etc. (Ajzen, 1991; Armitage \& Conner, 2001; Downs \& Hausenblas, 2005; Sutton, 1998). More recently, a metaanalysis of experimental studies showed that health behaviour change interventions significantly increase both intention $(d=.66)$ and behaviour $(d=.36$.), and that intention mediated the effect of the interventions on behaviour change (Webb \& Sheeran, 2006).

\section{Knowledge}

In social cognition models knowledge about the behaviour is a prerequisite for behaviour change, though an insufficient motivator in itself (Ogden, 2000). Two lines of inquiry about knowledge warrant attention in regard to falls prevention. First, a

Nyman, S. (2011). Psychosocial issues in engaging older people with physical activity interventions for the prevention of falls. Canadian Journal on Aging, 30(1), 45-55. 
study by Zecevic and colleagues showed that older people and health professionals did not define falls in the way that has been proposed in the literature, seemed preoccupied with the consequences of falls, and the term 'falls' may be interpreted as only in reference to injurious falls. The implication of this finding is that opportunities may be missed for talking about and preventing non-injurious falls that may help in preventing injurious falls (Zecevic, Salmoni, Speechley, \& Vandervoort, 2006). In addition, the term 'falls prevention' may be unfamiliar to older people (Commonwealth Department of Health and Aged Care, 2001).

Second, it appears that older people suggest means of reducing extrinsic risk factors for preventing falls rather than intrinsic (Commonwealth Department of Health and Aged Care, 2001; Horne, Speed, Skelton, \& Todd, 2009b; Yardley, Donovan-Hall, Francis, \& Todd, 2006b). Reducing extrinsic risk factors entails addressing the environment, such as making home modifications, using walking aids, and changing footwear (Commonwealth Department of Health and Aged Care, 2001). Reducing intrinsic risk factors entails addressing the individual's health, through medical examination and treatment or strength and balance training. In older persons, intrinsic risk factors may not be as obvious or easy to understand and accept as extrinsic risk factors (Commonwealth Department of Health and Aged Care, 2001; Horne et al., 2009b; Yardley et al., 2006b). For example, a UK qualitative study asked inpatients of an acute elderly care ward for their views and none of them offered physical activity as a means to prevent falls (Simpson, Darwin, \& Marsh, 2003). The influence of older people's knowledge that falls can be prevented through physical activity relates to the wider physical activity literature. It has been found that there is ignorance of the recommended amount of physical activity to be undertaken (Horne, Skelton, Speed, \& Nyman, S. (2011). Psychosocial issues in engaging older people with physical activity interventions for the prevention of falls. Canadian Journal on Aging, 30(1), 45-55. 
Todd, 2009a), that older people rarely walk at the intensity required to gain the health benefits of physical activity, and half of one sample was sedentary but felt that they were exercising sufficiently to receive health benefits (Skelton, Young, Walker, \& Hoinville, 1999). This also relates to the finding that some people believe that physical activity increases the risk of falls (Horne et al., 2009b), which is generally untrue (Peeters, van Schoor, Pluijm, Deeg, \& Lips, 2010), though brisk walking has been found to increase the risk of falls (Sherrington et al., 2008).

Thus, knowledge can influence older people's engagement in falls prevention interventions. In particular, communication about falls and their prevention with older people may be inhibited by a lack of a shared understanding of falls. Older people are also less likely to participate in falls prevention activities if they are not aware that falls can be prevented, that interventions such as physical activity can prevent falls, and the type, frequency, duration, and intensity of physical activities that are required to gain the health benefits that will prevent falls. However, knowledge is an insufficient motivator for the prevention of falls. For example, a survey in Canada with 477 participants found that although $78 \%$ knew of the importance of physical activity in the prevention of falls 52\% were sedentary (Zecevic et al., 2006). Thus, additional factors such as older people's attitudes may influence participation in falls prevention interventions.

\section{Attitude toward the behaviour}

According to the TPB, older people are more likely to carry out falls prevention activities when they perceive that they will bring positive benefits and that these benefits are highly likely to occur. Whilst falls are not an inevitable part of the ageing

Nyman, S. (2011). Psychosocial issues in engaging older people with physical activity interventions for the prevention of falls. Canadian Journal on Aging, 30(1), 45-55. 
process (Daleiden, 1990; Koch, Gottschalk, Baker, Palumbo, \& Tinetti, 1994), some may perceive falls as events that cannot be prevented. Falls may be perceived to be random events, determined by some ethereal force such as fate or God, or simply part of ageing. Indeed, an ethnographic study found that some of the South Asians in their sample believed a fall was God's judgement upon people. The authors concluded that if people believe that falls are inevitable or unpreventable then they are unlikely to engage in physical activities that prevent falls (Horne et al., 2009b). Dismissing a fall as either insignificant or a random event also serves as a way to protect the individual's self-identity because of the stigma attached to falls (Hanson, Salmoni, \& Doyle, 2009) (see later section on self-identity).

A particular behavioural belief that influences older people's attitudes towards falls prevention is perceived falls risk. This refers to optimistic bias, where people falsely believe that they are not as vulnerable to health risks as others (Weinstein, 1980). Perceived risk of falls among older people has been reported as at best below average (Braun, 1998; Cameron \& Quine, 1994; Ezendam, Alpay, Rövekamp, \& Toussaint, 2005; Health Education Board for Scotland [HEBS], 2001; Hughes et al., 2008; Nyman \& Yardley, 2009a; Simpson \& Mandelstam, 1995; Yardley et al., 2006a; 2006b). For example, an Australian survey was conducted with 389 older people in which participants were asked about their chance of falling and their peers' chance of falling in the next 12 months (Dollard, Turnbull, Newbury, \& Barton, 2008). Only $9.4 \%$ felt their risk of falls was higher than their peers, whereas $48.3 \%$ felt their risk of falls was lower than their peers. In addition, the $36 \%$ who had previously experienced a fall were more likely to rate their risk of falls as lower than their peers. Indeed, another study found that the prevalence of falls risk factors such as old age,

Nyman, S. (2011). Psychosocial issues in engaging older people with physical activity interventions for the prevention of falls. Canadian Journal on Aging, 30(1), 45-55. 
poor mobility, and the experience of previous falls did not lead to a greater perception of falls risk (Yardley et al., 2006a).

Though having a history of falls is a strong risk factor for further falls (Lord, Sherrington, Menz, \& Close, 2007), secondary falls (further falls after the first fall) can be prevented even in recurrent fallers (Spice et al., 2009). Most individuals appear to understand why they fell and this seems to facilitate engagement with falls prevention, reduce fear of falls, and enhance PBC for everyday functioning and activities (Roe et al., 2008). Older people may perceive a fall to have occurred because their body is ageing and has suffered a drop in functioning, termed the 'body drop'. The implication is that a person who attributes their fall to an internal and unpreventable cause is likely to see little point in engaging in activity to prevent further falls (McKee, 1998). Similarly, Kingston (2000) has referred to sociological theories of status passage and preferred identities to explain how older people who fall pass from a perceived healthy stage to a frail stage of life. A fall may be interpreted by older people in one of three ways with differing passage implications. An individual may brush off their fall as a one-off incident, especially if there was no injury from the fall, with no passage implications. Alternatively, an individual may treat their fall as a warning to be more vigilant and perhaps restrict behaviour, especially if they have mobility problems or chronic illnesses, with no passage implications. The final alternative is the body drop, especially among those who were physically active before they fell, a view that inhibits mobility and cooperation with rehabilitation (Kingston, 2000).

Nyman, S. (2011). Psychosocial issues in engaging older people with physical activity interventions for the prevention of falls. Canadian Journal on Aging, 30(1), 45-55. 
The body drop theory has been supported with studies that have followed-up inpatients who were admitted to hospital from a fall. At two months post-discharge, perceived recovered activity was predicted by believing the fall to be preventable and caused by extrinsic risk factors (McKee, Orbell, \& Radley, 1999). In addition, at six months post-discharge, ambulation was predicted by an attribution that the fall was caused by something they could identify, temporary, and had little impact on their independence and social connectedness (Borkan, Quirk, \& Sullivan, 1991).

Thus, attitudes can influence older people's engagement in falls prevention interventions. In particular, a belief that falls cannot be prevented and optimistic bias will inhibit intention to participate in falls prevention interventions. In terms of preventing secondary falls, if an individual understands why they fell and attributes the cause of their fall to an external and preventable cause this will facilitate their intention to participate in falls prevention interventions. Yet people do not make decisions about health behaviour in isolation, and so the social context must also be considered.

\section{Subjective norm}

According to the TPB, older people will be more likely to engage in falls prevention activities when they anticipate or receive favourable opinions from significant others and when they are motivated to accept and respond to them. This notion is supported by the widespread finding that people are more likely to carry out physical activity if they are socially supported by a significant other (Buckworth \& Dishman, 2002; Paxton, Browning, \& O'Connell, 1997; Sallis, Hovell, Hofstetter, \& Barrington, 1992; Shephard, 1994).

Nyman, S. (2011). Psychosocial issues in engaging older people with physical activity interventions for the prevention of falls. Canadian Journal on Aging, 30(1), 45-55. 
Health professionals are influential with older people's health knowledge and behaviour (Booth, Bauman, Owen, \& Gore, 1997; Commonwealth Department of Health and Aged Care, 2001; Horne et al., 2009a). An overly medical approach to understanding the causes and consequences of falls can overlook the psychosocial determinants of engagement in rehabilitation to prevent further falls. For example, general practice nurses have been found to report believing that falls are both inevitable and signal an increase in dependency on healthcare staff: "[a fall] marks the beginning of the end" (Thomas, 1997, p. 155). Such an approach to falls may inhibit older people's attempts to prevent falls through a lack of social support or disapproving comments. A similar finding has also been found with occupational therapists and physiotherapists (Ballinger \& Payne, 2000).

In addition, a discrepancy in priorities can emerge between older people and healthcare staff. An ethnographic study with older people at a day hospital found that service providers were concerned with physical safety, creating dependency in service users, and disempowered initiative and activity. In contrast, service users were concerned with their social well-being, and threats to their independence and selfidentity (Ballinger \& Payne, 2002). Thus, healthcare professionals can be both overly cautious about reducing the risk of falls, and miss opportunities to engage older people in falls prevention by focusing on issues relating to their agenda rather than that of the older person, which may be more to do with social well-being. Therefore, a socially supportive environment will facilitate older people's participation in falls prevention interventions, particularly those that foster and boost perceived behavioural control.

Nyman, S. (2011). Psychosocial issues in engaging older people with physical activity interventions for the prevention of falls. Canadian Journal on Aging, 30(1), 45-55. 


\section{Perceived behavioural control}

Perceived behavioural control (PBC) is the degree of confidence a person has about performing a behaviour, given the social and environmental context that may or may not be conducive. For physical activity, PBC has been shown to be an important determinant as adults with a high level of PBC are consistently reported as more physically active (Brassington, Atienza, Perczek, DiLorenzo, \& King, 2002; Buckworth \& Dishman, 2002; Burton, Shapiro, \& German, 1999; King et al., 1992; McAuley, Jerome, Elavsky, Marquez, \& Ramsey, 2003; Paxton et al., 1997; Resnick, Palmer, Jenkins, \& Spellbring, 2000; Rodgers \& Brawley, 1993; Sallis et al., 1992; Stead, Wimbush, Eadie, \& Teer, 1997). Perceived behavioural control is also predictive of recovery of functioning in older people undergoing rehabilitation (Jacelon, 2007). In contrast, fear of falling can pose a barrier to participation in falls prevention interventions that use physical activity / strength and balance training.

The prevalence of fear of falls in community-dwelling older people has been widely estimated at $20-85 \%$ (Zijlstra et al., 2007). This wide range in prevalence is explained by the heterogeneity in measures used and variance in the use of such measures (Jørstad, Hauer, Becker, \& Lamb, 2005). A consequence of being afraid of falling is that individuals can prematurely restrict their lifestyle (Howland, Peterson, Levin, \& Fried, 1993; Tinetti, Deleon, Doucette, \& Baker, 1994; Tinetti \& Powell, 1993; WardGriffin et al., 2004; Yardley \& Smith, 2002). A community survey in the Netherlands found that $54.3 \%$ of over four thousand older people were afraid of falling and $37.9 \%$ were restricting their lifestyles (Zijlstra et al., 2007). Fear of fall-related activity restriction has similarly been widely estimated at 15-55\% (Zijlstra et al., 2007).

Nyman, S. (2011). Psychosocial issues in engaging older people with physical activity interventions for the prevention of falls. Canadian Journal on Aging, 30(1), 45-55. 
Given the well document evidence for physical activities to bring a number of health benefits including the prevention of falls (Chang et al., 2004; Gillespie et al., 2009; Sherrington et al., 2008), the undue restriction of activities can lead to an increase in falls (Yardley, 1998; 2004). This behaviour can lead to the downward spiral of 'postfall syndrome', whereby a person's balance becomes impaired, they fall, and the fall leads to further impairment of balance and falls risk (Murphy \& Isaacs, 1982). Most research has investigated the prevalence, risks, and consequences of fear of falls (Scheffer, Schuurmans, van Dijk, van der Hooft, \& de Rooij, 2008), with little work into its impact on participation in falls prevention interventions. However, studies have highlighted lower levels of activity in older people afraid of falls. Fear of falling has independently predicted lower levels of recreational physical activity in older women (odds ratio $[\mathrm{OR}]=0.70)($ Bruce, Devine, $\&$ Prince, 2002), and fear of moving outdoors has predicted difficulty in walking $0.5 \mathrm{~km}$ (adjusted OR =4.60) and $2 \mathrm{~km}$ (adjusted OR = 3.10) just six months later (Rantakokko et al., 2009). In addition, inpatients admitted due to a fall-related hip fracture who are worried about falling and have poor perceived behavioural control are more likely to fall two months postdischarge (McKee et al., 2002).

Whilst fear of falls is linked with an increased risk of falls ( $\mathrm{OR}=1.29, r=0.19)$ (Delbaere, Close, Brodaty, Sachdev, \& Lord, 2010), people may be afraid of falls even if they are not at risk of a fall, and those that are at risk of a fall may not necessarily be afraid of falling (Delbaere et al., 2010; Fortinsky, Panzer, Wakefield, \& Into, 2009; Yardley, 2004). Whilst younger age and better health is associated with less fear of falls (Delbaere et al., 2010; Fortinsky et al., 2009), perhaps such discrepancies in fear of falls can be explained by people's general perception of risk Nyman, S. (2011). Psychosocial issues in engaging older people with physical activity interventions for the prevention of falls. Canadian Journal on Aging, 30(1), 45-55. 
and personality (Delbaere et al., 2010). It is theorised that such people who are afraid of falls and restrict their level of physical and social activity will do so even when participating in strength and balance training interventions that reduce the risk of falls. Indeed, such people may restrict their activity even further so that their reduction in risk of falls in the short-term post-intervention is actually because of a decrease in exposure to risk from a restriction in activity, and such activity restriction will actually increase their risk of falls in the long-term (Laybourne, Biggs, \& Martin, 2008).

Therefore, high levels of perceived behavioural control will facilitate older people's participation in falls prevention interventions. Fear of falls can lead older people to restrict their lifestyles, withdraw from participation in physical activity and strength and balance training that prevents falls, and therefore increase their risk of falling. Before intention is discussed - the variable predicted by attitude toward the behaviour, subjective norm, and perceived behavioural control - one additional variable is considered.

\section{Self-identity}

Self-identity refers to the level of similarity an individual perceives with themselves and the typical person who engages in a given behaviour (Conner \& Armitage, 1998). Engagement with behaviour that is consistent with self-identity validates an individual's role and identity, whereas non-participation creates a conflict between their identity and actions (cognitive dissonance) (Festinger, 1957; Fielding, McDonald, \& Louis, 2008). Self-identity is distinguished from social identity that refers to the shared identity an individual has when they ally themselves to a group,

Nyman, S. (2011). Psychosocial issues in engaging older people with physical activity interventions for the prevention of falls. Canadian Journal on Aging, 30(1), 45-55. 
which influences them to adhere to group expectations and behave less like nonmembers (Fielding et al., 2008).

In the falls literature there is a strong indication that the preservation of self-identity is pertinent to older people's engagement in interventions in relation to stigma. Stigma is "the situation of the individual who is disqualified from full social acceptance" (Goffman, 1963, p. 9). Stigma can be health-related, and is characterised by exclusion, rejection, blame, or devaluation. In one study the term 'faller' had connotations of the person being frail, dependent, and possibly having a drink problem (HEBS, 2001). Thus, stigma is placed upon an older person or group of older people ('fallers') who have or are anticipated to experience a fall that is associated with undesirable social judgement (Weiss \& Ramakrishna, 2006). The stigma of falls is also seated within the wider issue of dependency, whereby older people appear deeply concerned with not being perceived as a burden on others (Belza et al., 2004; Furstenberg, 1986; Hanson et al., 2009; HEBS, 2001; Takahashi \& Asakawa, 2005). By stigmatising falls and distancing oneself from fallers, the older person is simultaneously able to portray themselves as different, as one who is competent, healthy (Buttery \& Martin, 2009; Hughes et al., 2008), independent (Hughes et al., 2008), and not at risk of falling (Ballinger \& Payne, 2000; 2002; Simpson et al., 2003).

The stigma of falls and preservation of one's self-identity has implications on how falls prevention information and advice is communicated (Nyman, 2007) because older people will not readily identify with the group labelled as 'fallers' (Hanson et al., 2009). As falls are generally considered to be experienced by a group older and Nyman, S. (2011). Psychosocial issues in engaging older people with physical activity interventions for the prevention of falls. Canadian Journal on Aging, 30(1), 45-55. 
frailer than the older person in question (Braun, 1998; Cameron \& Quine, 1994;

Ezendam et al., 2005; HEBS, 2001; Hughes et al., 2008; Nyman \& Yardley, 2009a; Simpson \& Mandelstam, 1995; Yardley et al., 2006a; 2006b), older people may not identify themselves as 'old' because of the negative connotations associated with old age in terms of infirmity and senility (Hanson et al., 2009; Stead et al., 1997). This would also explain why older people may not want to make adjustments to their home that would make it look like a nursing home (Connell, 1996).

Thus, the preservation of self-identity and avoidance of stigma influences older people's engagement in falls prevention interventions. Older people appear much more likely to engage in interventions that fit with a positive self-identity and emphasise the positive benefits of interventions, rather than those that seek to raise older people's self-perceived risk of falls and motivation to reduce this risk (Ballinger \& Clemson, 2006; HEBS, 2001; Horne et al., 2009b; Hughes et al., 2008; Nyman, 2007; Yardley et al., 2006a; 2006b). This inference is supported in the research discussed in the next section on intention.

\section{Intention}

Based on the TPB, the Attitudes to Fall-Related Interventions Scale (AFRIS) has been developed and validated to measure older people's intention to undertake falls prevention activities (Prevention of Falls Network Europe, 2006; Yardley et al., 2007b). The scale has been used in a survey that investigated whether negative or positive factors predicted intention to undertake strength and balance training (to prevent falls). The negative factors were health conditions that increase the risk of falls, perceived risk of falls, and fear of falls, and these factors did not significantly

Nyman, S. (2011). Psychosocial issues in engaging older people with physical activity interventions for the prevention of falls. Canadian Journal on Aging, 30(1), 45-55. 
predict intention to undertake strength and balance training (regression weight $=.09$ ) . In contrast, the positive factors were the constructs from the TPB (attitude, subjective norm, and PBC) plus self-identity, which positively predicted intention (regression weight $=.87)$ (Yardley et al., 2007b). While further research is required to determine whether intention is highly predictive of falls prevention behaviour such as strength and balance training, it is clear from this study that the positive benefits of falls prevention activities should be emphasised to engage older people in strength and balance training. This is supported by other studies that have identified positive factors as motivators for older people to undertake strength and balance training, including: maintaining independence, social networking, enjoyment, weight reduction, learning new things, building confidence, and looking and feeling good (Ballinger \& Clemson, 2006; Horne, Skelton, \& Todd, 2005; Yardley et al., 2006a).

The AFRIS was also used in a study that compared two different formats of presenting the same strength and balance training advice. Using a website, the advice was either presented in a generic format typically used on websites and leaflets, in that it adopted a 'one size fits all' approach (Kreuter, Strecher, \& Glassman, 1999). The other version of the advice was tailored to the individual based on their self-rated balance ability, preferred format of activity (in or around the home, outside, and / or class-based), preferred activities, and falls risk-related health conditions (for information on tailoring see Kreuter, Farrell, Olevitch, \& Brennan, 2000). This study found that participants who received the tailored version reported the advice to be more personally relevant (additional measure) and that the activities would be good for them, though the overall measure and the item for intention to undertake strength and balance training was not significantly different to the generic group (Nyman \& Nyman, S. (2011). Psychosocial issues in engaging older people with physical activity interventions for the prevention of falls. Canadian Journal on Aging, 30(1), 45-55. 
Yardley, 2009b). The study was a partial replication of an earlier study that found the tailored version was reported to be more personally relevant and participants reported greater $\mathrm{PBC}$ and intention to undertake strength and balance training than peers who viewed the generic version (Yardley \& Nyman, 2007). A meta-analysis of the two studies found the tailored version to receive higher ratings of personal relevance and intention to undertake strength and balance training (Nyman \& Yardley, 2009b).

\section{ProFaNE recommendations}

From expert consensus, the Prevention of Falls Network Europe (ProFaNE) have generated a set of six recommendations for promoting older people's uptake and adherence to falls-related interventions (Yardley et al., 2007a). Whilst suggestions have been made on how to implement these guidelines in practice (Nyman \& Ballinger, 2008), it may take some time for these recommendations to be acted upon. A recent qualitative study examined falls prevention websites for the image of older people implicitly projected in the advice. This study found that websites predominantly used an image of older people that was not consistent with the two ProFaNE recommendations that interventions should be promoted in a manner that fits with a positive self-identity and empowers individuals to be self-reliant in their healthcare. Older people were generally presented with advice that implied that they were victims of the ageing process, with age-related declines in faculties and functioning, and were incapable of taking care of their health (Nyman, Hogarth, Ballinger, \& Victor, 2009).

Nyman, S. (2011). Psychosocial issues in engaging older people with physical activity interventions for the prevention of falls. Canadian Journal on Aging, 30(1), 45-55. 


\section{Conclusion}

Using the theory of planned behaviour, this review has provided an overview of the psychosocial factors that can act as barriers or facilitators for older people to take up and adhere to physical activity interventions for the prevention of falls. It was explained that knowledge, attitudes, subjective norm, perceived behavioural control, and self-identity can influence older people's intention to undertake falls prevention activities. More specifically, older people will be more likely to engage with falls prevention interventions if they are presented in a manner that fits with a positive selfidentity and emphasises the positive benefits, and if older people have a high level of perceived behavioural control and a socially supportive environment. For older people who have fallen, if they understand why they fell and attribute the cause of their fall to external and preventable causes then they will be more likely to engage in interventions to prevent secondary falls. Health professionals are advised to bear in mind these psychosocial factors and in particular the evidence-based recommendations made by ProFaNE. If interventions that effectively reduce falls are designed and delivered in a manner that psychosocially maximises their appeal to older people and facilitates their sustained participation, this will make for a powerful combination that should reduce falls and increase quality of life in older people.

Nyman, S. (2011). Psychosocial issues in engaging older people with physical activity interventions for the prevention of falls. Canadian Journal on Aging, 30(1), 45-55. 


\section{Acknowledgements}

The author thanks Veronica Heath for providing a French translation of the abstract, and Dr Maggie Donovan-Hall and Professor Christina Victor for their comments on an earlier draft of this paper.

Nyman, S. (2011). Psychosocial issues in engaging older people with physical activity interventions for the prevention of falls. Canadian Journal on Aging, 30(1), 45-55. 


\section{References}

Ajzen, I. (1988). Attitudes, personality, and behavior. Milton Keynes, UK: Open University Press.

Ajzen, I. (1991). The theory of planned behavior. Organizational Behavior and Human Decision Processes, 50, 179-211.

Ajzen, I. (2006). TPB diagram. Retrieved October 23, 2009, from: http://people.umass.edu/aizen/tpb.diag.html

Armitage, C. J., \& Conner, M. (2001). Efficacy of the theory of planned behaviour: A meta-analytic review. British Journal of Social Psychology, 40, 471-499.

Ballinger, C., \& Clemson, L. (2006). Older people's views about community falls prevention: An Australian perspective. British Journal of Occupational Therapy, 69, 263-270.

Ballinger, C., \& Payne, S. (2000). Falling from grace or into expert hands? Alternative accounts about falling in older people. British Journal of Occupational Therapy, 63, 573-579.

Ballinger, C., \& Payne, S. (2002). The construction of the risk of falling among and by older people. Ageing \& Society, 22, 305-324.

Belza, B., Walwick, J., Shiu-Thornton, S., Schwartz, S., Taylor, M., \& LoGerfo, J. (2004). Older adults perspectives on physical activity and exercise: Voices from multiple cultures. Preventing Chronic Disease, 1, 1-12.

Nyman, S. (2011). Psychosocial issues in engaging older people with physical activity interventions for the prevention of falls. Canadian Journal on Aging, 30(1), 45-55. 
Booth, M. L., Bauman, A., Owen, N., \& Gore, C. J. (1997). Physical activity preferences, preferred sources of assistance, and perceived barriers to increased activity among physically inactive Australians. Preventive Medicine, $26,131-137$

Borkan, J. M., Quirk, M., \& Sullivan, M. (1991). Finding meaning after the fall: Injury narratives from elderly hip fracture patients. Social Science \& Medicine, 33, 947-957.

Brassington, G. S., Atienza, A., Perczek, R. E., DiLorenzo, T. M., \& King, A. C. (2002). Intervention-related cognitive versus social mediators of exercise adherence in the elderly. American Journal of Preventive Medicine, 23, 80-86.

Braun, B. L. (1998). Knowledge and perception of fall-related risk factors and fallreduction techniques among community-dwelling elderly individuals. Physical Therapy, 78, 1262-1276.

Bruce, D. G., Devine, A., \& Prince, R. L. (2002). Recreational physical activity levels in healthy older women: The importance of fear of falling. Journal of the American Geriatrics Society, 50, 84-89.

Buckworth, J., \& Dishman, R. K. (2002). Exercise psychology. Leeds, UK: Human Kinetics.

Bunn, F., Dickinson, A., Barnett-Page, E., McInnes, E., \& Horton, K. (2008). A systematic review of older people's perceptions of facilitators and barriers to participation in falls-prevention interventions. Ageing \& Society, 28, 449-472.

Nyman, S. (2011). Psychosocial issues in engaging older people with physical activity interventions for the prevention of falls. Canadian Journal on Aging, 30(1), 45-55. 
Burton, L. C., Shapiro, S., \& German, P. S. (1999). Determinants of physical activity initiation and maintenance among community-dwelling older persons. Preventive Medicine, 29, 422-430.

Buttery, A. K., \& Martin, F. C. (2009). Knowledge, attitudes and intentions about participation in physical activity of older post-acute hospital inpatients. Physiotherapy, 95, 192-198.

Cameron, I. D., \& Quine, S. (1994). External hip protectors: Likely noncompliance among high-risk elderly people living in the community. Archives of Gerontology and Geriatrics, 19, 273-281.

Campbell, A. J., Robertson, M. C., Gardner, M. M., Norton, R. N., \& Buchner, D. M. (1999). Falls prevention over 2 years: A randomized controlled trial in women 80 years and older. Age and Ageing, 28, 513-518.

Chang, J. T., Morton, S. C., Rubenstein, L. Z., Mojica, W. A., Maglione, M., Suttorp, M. J. et al. (2004). Interventions for the prevention of falls in older adults: Systematic review and meta-analysis of randomised clinical trials. BMJ, 328, $680-683$.

Chao, D., Foy, C. G., \& Farmer, D. (2000). Exercise adherence among older adults: Challenges and strategies. Controlled Clinical Trials, 21, 212S-217S.

Commonwealth Department of Health and Aged Care. (2001). National falls prevention for older people initiative "step out with confidence": A study into the information needs and perceptions of older Australians concerning falls and their prevention. Canberra: Commonwealth of Australia.

Nyman, S. (2011). Psychosocial issues in engaging older people with physical activity interventions for the prevention of falls. Canadian Journal on Aging, 30(1), 45-55. 
Connell, B. R. (1996). Role of the environment in falls prevention. Clinics in Geriatric Medicine, 12, 859-880.

Conner, M., \& Armitage, C. J. (1998). Extending the theory of planned behavior: A review and avenues for further research. Journal of Applied Social Psychology, 28, 1429-1464.

Daleiden, S. (1990). Prevention of falling: Rehabilitative or compensatory interventions? Topics in Geriatric Rehabilitation, 5, 44-53.

Day, L., Fildes, B., Gordon, I., Fitzharris, M., Flamer, H., \& Lord, S. (2002). Randomised factorial trial of falls prevention among older people living in their own homes. BMJ, 325, 128-131.

Delbaere, K., Close, J. C. T., Brodaty, H., Sachdev, P., \& Lord, S. R. (2010). Determinants of disparities between perceived and physiological risk of falling among elderly people: Cohort study. BMJ, 341, Published Online First: 18 August, doi: 10.1136/bmj.

Dollard, J., Turnbull, D., Newbury, J., \& Barton, C. (2008). Older people are comparably optimistic towards falling. Paper presented at the 3rd Australian and New Zealand Falls Prevention Conference, Melbourne, Australia.

Downs, D. S., \& Hausenblas, H. A. (2005). The theories of reasoned action and planned behavior applied to exercise: A meta-analytic update. Journal of Physical Activity and Health, 2, 76-97.

Dracup, K. A., \& Meleis, A. I. (1982). Compliance: An interactionist approach. Nursing Research, 31, 31-36.

Nyman, S. (2011). Psychosocial issues in engaging older people with physical activity interventions for the prevention of falls. Canadian Journal on Aging, 30(1), 45-55. 
Ezendam, N. P. M., Alpay, L. L., Rövekamp, T. A. J. M., \& Toussaint, P. J. (2005). Experimenting with case-based reasoning to present educative health information on the internet: The example of SeniorGezond. In R. Engelbrecht, A. Geissbuhler, C. Lovis, \& G. Mihalas (Eds.), Connecting medical informatics and bio-informatics: Proceedings of MIE2005 - The XIXth international congress of the European Federation for Medical Informatics, vol 116 (pp. 867-872). Geneva: IOS Press.

Festinger, L. (1957). A theory of cognitive dissonance. Stanford, CA: Stanford University Press.

Fielding, K. S., McDonald, R., \& Louis, W. R. (2008). Theory of planned behaviour, identity and intentions to engage in environmental activism. Journal of Environmental Psychology, 28, 318-326.

Fortinsky, R. H., Panzer, V., Wakefield, D., \& Into, F. (2009). Alignment between balance confidence and fall risk in later life: Has over-confidence been overlooked? Health, Risk \& Society, 11, 341-352.

Furstenberg, A.-L. (1986). Expectations about outcome following hip fracture among older people. Social Work in Health Care, 11, 33-47.

Gillespie, L. D., Robertson, M. C., Gillespie, W. J., Lamb, S. E., Gates, S., Cumming, R. G. et al. (2009). Interventions for preventing falls in older people living in the community. Cochrane Database of Systematic Reviews, 2, Art. No.: CD007146, DOI: 10.1002/14651858.CD007146.pub2.

Nyman, S. (2011). Psychosocial issues in engaging older people with physical activity interventions for the prevention of falls. Canadian Journal on Aging, 30(1), 45-55. 
Goffman, E. (1963). Stigma: Notes on the management of spoiled identity. NJ: Prentice-Hall Inc.

Hanson, H. M., Salmoni, A. W., \& Doyle, P. C. (2009). Broadening our understanding: Approaching falls as a stigmatizing topic for older adults. Disability and Health Journal, 2, 36-44.

Health Education Board for Scotland [HEBS]. (2001). The construction of the risks of falling in older people: Lay and professional perspectives. Edinburgh: Health Education Board for Scotland.

Horne, M., Skelton, D., Speed, S., \& Todd, C. (2009a). The influence of primary health care professionals in encouraging exercise and physical activity uptake among White and South Asian older adults: Experiences of young older adults. Patient Education \& Counseling, Published Online First: May 12, doi10.1016/j.pec.2009.04.004.

Horne, M., Skelton, D. A., \& Todd, C. J. (2005). Attitudes and beliefs about the uptake and adherence of exercise and physical activity in 60 - 70 year olds in relation to fall prevention. Poster presented at the British Psychological Society Annual Conference, Coventry, UK.

Horne, M., Speed, S., Skelton, D., \& Todd, C. (2009b). What do community-dwelling Caucasian and South Asian 60-70 year olds think about exercise for fall prevention? Age and Ageing, 38, 68-73.

Howland, J., Peterson, E. W., Levin, W. C., \& Fried, L. (1993). Fear of falling among the community-dwelling elderly. Journal of Aging \& Health, 5, 229-243.

Nyman, S. (2011). Psychosocial issues in engaging older people with physical activity interventions for the prevention of falls. Canadian Journal on Aging, 30(1), 45-55. 
Hughes, K., van Beurden, E., Eakin, E. G., Barnett, L. M., Patterson, E., Backhouse, J. et al. (2008). Older persons' perception of risk of falling: Implications for fall-prevention campaigns. American Journal of Public Health, 98, 351-357.

Jacelon, C. S. (2007). Theoretical perspectives of perceived control in older adults: A selective review of the literature. Journal of Advanced Nursing, 59, 1-10.

Jørstad, E. C., Hauer, K., Becker, C., \& Lamb, S. E. (2005). Measuring the psychological outcomes of falling: A systematic review. Journal of the American Geriatrics Society, 53, 501-510.

King, A. C., Blair, S. N., Bild, D. E., Dishman, R. K., Dubbert, P. M., Marcus, B. H. et al. (1992). Determinants of physical activity and interventions in adults. Medicine and Science in Sports and Exercise, 24, S221-S236.

Kingston, P. (2000). Falls in later life: Status passage and preferred identities as a new orientation. Health, 4, 216-233.

Koch, M., Gottschalk, M., Baker, D. I., Palumbo, S., \& Tinetti, M. E. (1994). An impairment and disability assessment and treatment protocol for communityliving elderly persons. Physical Therapy, 74, 286-294.

Kreuter, M. W., Farrell, D., Olevitch, L., \& Brennan, L. (2000). Tailoring health messages: Customizing communication with computer technology. Mahwah, NJ: Lawrence Erlbaum Associates.

Kreuter, M. W., Strecher, V. J., \& Glassman, B. (1999). One size does not fit all: The case for tailoring print materials. Annals of Behavioral Medicine, 21, 276-283.

Nyman, S. (2011). Psychosocial issues in engaging older people with physical activity interventions for the prevention of falls. Canadian Journal on Aging, 30(1), 45-55. 
Kyngas, H., Duffy, M. E., \& Kroll, T. (2000). Conceptual analysis of compliance. Journal of Clinical Nursing, 9, 5-12.

Laybourne, A. H., Biggs, S., \& Martin, F. C. (2008). Falls exercise interventions and reduced falls rate: Always in the patient's interest? Age and Ageing, 37, 10-13.

Lord, S. R., Sherrington, C., Menz, H. B., \& Close, J. C. T. (2007). Falls in older people: Risk factors and strategies for prevention (2nd ed.). Cambridge, UK: Cambridge University Press.

McAuley, E., Jerome, G. J., Elavsky, S., Marquez, D. X., \& Ramsey, S. N. (2003). Predicting long-term maintenance of physical activity in older adults. Preventive Medicine, 37, 110-118.

McKee, K. J. (1998). The body drop: A framework for understanding recovery from falls in older people. Generations Review, 8, 11-12.

McKee, K. J., Orbell, S., Austin, C. A., Bettridge, R., Liddle, B. J., Morgan, K. et al. (2002). Fear of falling, falls efficacy, and health outcomes in older people following hip fracture. Disability and Rehabilitation, 24, 327-333.

McKee, K. J., Orbell, S., \& Radley, K. A. (1999). Predicting perceived recovered activity in older people after a fall. Disability and Rehabilitation, 21, 555-562.

Murphy, J., \& Isaacs, B. (1982). The post-fall syndrome: A study of 36 elderly patients. Gerontology, 28, 265-270.

Nyman, S. R. (2007). A balancing act? Samuel R. Nyman, winner in the postgraduate category, on ways of preventing falls in older people without creating a stigma. The Psychologist, 20, 420-421.

Nyman, S. (2011). Psychosocial issues in engaging older people with physical activity interventions for the prevention of falls. Canadian Journal on Aging, 30(1), 45-55. 
Nyman, S. R., \& Ballinger, C. (2008). A review to explore how allied health professionals can improve uptake of and adherence to falls prevention interventions. British Journal of Occupational Therapy, 71, 141-145.

Nyman, S. R., Hogarth, H., Ballinger, C., \& Victor, C. R. (2009). Representations of old age in falls prevention websites: Implications for likely uptake of advice by older people. Manuscript submitted for publication.

Nyman, S. R., \& Yardley, L. (2009a). Usability and acceptability of a website that provides tailored advice on falls prevention activities for older people. Health Informatics Journal, 15, 27-39.

Nyman, S. R., \& Yardley, L. (2009b). Web-site-based tailored advice to promote strength and balance training: An experimental evaluation. Journal of Aging and Physical Activity, 17, 210-222.

Ogden, J. (2000). Health psychology: A textbook (2nd ed.). Buckingham, UK: Open University Press.

Paxton, S. J., Browning, C. J., \& O'Connell, G. (1997). Predictors of exercise program participation in older women. Psychology \& Health, 12, 543-552.

Peeters, G. M., van Schoor, N. M., Pluijm, S. M., Deeg, D. J., \& Lips, P. (2010). Is there a U-shaped association between physical activity and falling in older persons? Osteoporosis International, 21, 1189-1195.

Prevention of Falls Network Europe. (2006). Questionnaire to assess attitudes to balance and falling-related interventions. Retrieved July 11, 2006, from: http://www.profane.eu.org/afris.php?PHPSESSID=d8bd5f5d4e3bcead8f9fe12 $\operatorname{ddf} 17 \mathrm{~cd} 00$.

Nyman, S. (2011). Psychosocial issues in engaging older people with physical activity interventions for the prevention of falls. Canadian Journal on Aging, 30(1), 45-55. 
Rantakokko, M., Mänty, M., Iwarsson, S., Törmäkangas, T., Leinonen, R., Heikkinen, E. et al. (2009). Fear of moving outdoors and development of outdoor walking difficulty in older people. Journal of the American Geriatrics Society, 57, 634640.

Resnick, B., Palmer, H., Jenkins, L. S., \& Spellbring, A. M. (2000). Path analysis of efficacy expectations and exercise behaviour in older adults. Journal of Advanced Nursing, 31, 1309-1315.

Rodgers, W. M., \& Brawley, L. R. (1993). Using both self-efficacy theory and the theory of planned behavior to discriminate adherers and dropouts from structured programs. Journal of Applied Sport Psychology, 5, 195-206.

Roe, B., Howell, F., Riniotis, K., Beech, R., Crome, P., \& Ong, B. N. (2008). Older people's experience of falls: Understanding, interpretation and autonomy. Journal of Advanced Nursing, 63, 586-596.

Sallis, J. F., Hovell, M. F., Hofstetter, C. R., \& Barrington, E. (1992). Explanation of vigorous physical-activity during 2 years using social-learning variables. Social Science \& Medicine, 34, 25-32.

Scheffer, A. C., Schuurmans, M. J., van Dijk, N., van der Hooft, T., \& de Rooij, S. E. (2008). Fear of falling: Measurement strategy, prevalence, risk factors and consequences among older persons. Age and Ageing, 37, 19-24.

Shekelle, P. G., Maglione, M., Chang, J. T., Mojica, W., Morton, S. C., Suttorp, M. et al. (2003). Falls prevention interventions in the Medicare population. Baltimore, MD: RAND.

Nyman, S. (2011). Psychosocial issues in engaging older people with physical activity interventions for the prevention of falls. Canadian Journal on Aging, 30(1), 45-55. 
Shephard, R. J. (1994). Determinants of exercise in people aged 65 years and older. In R. K. Dishman (Ed.), Advances in exercise adherence (pp. 343-360). Leeds, UK: Human Kinetics.

Sherrington, C., Whitney, J. C., Lord, S. R., Herbert, R. D., Cumming, R. G., \& Close, J. C. T. (2008). Effective exercise for the prevention of falls: A systematic review and meta-analysis. Journal of the American Geriatrics Society, 56, 2234-2243.

Simpson, J. M., Darwin, C., \& Marsh, N. (2003). What are older people prepared to do to avoid falling? A qualitative study in London. British Journal of Community Nursing, 8, 152-159.

Simpson, J. M., \& Mandelstam, H. (1995). Elderly people at risk of falling: Do they want to be taught how to get up again? Clinical Rehabilitation, 9, 65-69.

Skelton, D. A., Young, A., Walker, A., \& Hoinville, E. (1999). Physical activity in later life: Further analysis of the Allied Dunbar national fitness survey and the Health Education Authority national survey of activity and health. London: Health Education Authority.

Spice, C. L., Morotti, W., George, S., Denta, T. H. S., Rose, J., Harris, S. et al. (2009). The Winchester falls project: A randomised controlled trial of secondary prevention of falls in older people. Age and Ageing, 38, 33-40.

Stead, M., Wimbush, E., Eadie, D., \& Teer, P. (1997). A qualitative study of older people's perceptions of ageing and exercise: The implications for health promotion. Health Education Journal, 56, 3-16.

Nyman, S. (2011). Psychosocial issues in engaging older people with physical activity interventions for the prevention of falls. Canadian Journal on Aging, 30(1), 45-55. 
Stoop, A. P., van't Riet, A., \& Berg, M. (2004). Using information technology for patient education: Realizing surplus value? Patient Education \& Counseling, $54,187-195$.

Sutton, S. (1998). Predicting and explaining intentions and behavior: How well are we doing? Journal of Applied Social Psychology, 28, 1317-1338.

Takahashi, R., \& Asakawa, Y. (2005). Young-old and old-old motivation in cooperative fall-prevention programmes. Age and Ageing, 34, 90-92.

Thomas, E. P. A. (1997). Falls, the beginning of the end: A qualitative study with older people and practice nurses. Unpublished doctoral thesis, University of Southampton, UK.

Tinetti, M. E., Deleon, C. F. M., Doucette, J. T., \& Baker, D. I. (1994). Fear of falling and fall-related efficacy in relationship to functioning among communityliving elders. Journal of Gerontology, 49, M140-M147.

Tinetti, M. E., \& Powell, L. (1993). Fear of falling and low self-efficacy: A cause of dependence in elderly persons. Journals of Gerontology, 48, 35-38.

Ward-Griffin, C., Hobson, S., Melles, P., Kloseck, M., Vandervoort, A., \& Crilly, R. (2004). Falls and fear of falling among community-dwelling seniors: The dynamic tension between exercising precaution and striving for independence. Canadian Journal on Aging, 23, 307-318.

Webb, T. L., \& Sheeran, P. (2006). Does changing behavioral intentions engender behavior change? A meta-analysis of the experimental evidence. Psychological Bulletin, 132, 249-268.

Nyman, S. (2011). Psychosocial issues in engaging older people with physical activity interventions for the prevention of falls. Canadian Journal on Aging, 30(1), 45-55. 
Weinstein, N. D. (1980). Unrealistic optimism about future life events. Journal of Personality and Social Psychology, 39, 806-820.

Weiss, M. G., \& Ramakrishna, J. (2006). Stigma interventions and research for international health. Lancet, 367, 536-538.

Yardley, L. (1998). Fear of imbalance and falling. Reviews in Clinical Gerontology, 8, 23-29.

Yardley, L. (2004). Fear of falling: Links between imbalance and anxiety. Reviews in Clinical Gerontology, 13, 1-7.

Yardley, L., Beyer, N., Hauer, K., McKee, K. J., Ballinger, C., \& Todd, C. J. (2007a). Recommendations for promoting the engagement of older people in activities to prevent falls. Quality and Safety in Health Care, 16, 230-234.

Yardley, L., Bishop, F. L., Beyer, N., Hauer, K., Kempen, G. I. J. M., Piot-Ziegler, C. et al. (2006a). Older people's views of falls prevention interventions in six European countries. The Gerontologist, 46, 650-660.

Yardley, L., Donovan-Hall, M., Francis, K., \& Todd, C. J. (2006b). Older people's views of advice about falls prevention: A qualitative study. Health Education Research, 21, 508-517.

Yardley, L., Donovan-Hall, M., Francis, K., \& Todd, C. J. (2007b). Attitudes and beliefs that predict older people's intention to undertake strength and balance training. Journal of Gerontology: Psychological Sciences, 62B, P119-P125.

Nyman, S. (2011). Psychosocial issues in engaging older people with physical activity interventions for the prevention of falls. Canadian Journal on Aging, 30(1), 45-55. 
Yardley, L., \& Nyman, S. R. (2007). Internet provision of tailored advice on falls prevention activities for older people: A randomized controlled evaluation. Health Promotion International, 22, 122-128.

Yardley, L., \& Smith, H. (2002). A prospective study of the relationship between feared consequences of falling and avoidance of activity in community-living older people. The Gerontologist, 42, 17-23.

Zecevic, A. A., Salmoni, A. W., Speechley, M., \& Vandervoort, A. A. (2006). Defining a fall and reasons for falling: Comparisons among the views of seniors, health care providers, and the research literature. The Gerontologist, 46, 367-376.

Zijlstra, G. A. R., van Haastregt, J. C. M., van Eijk, J. Th. M., van Rossum, E., Stalenhoef, P. A., \& Kempen, G. I. J. M. (2007). Prevalence and correlates of fear of falling, and associated avoidance of activity in the general population of community-living older people. Age and Ageing, 36, 304-309.

Nyman, S. (2011). Psychosocial issues in engaging older people with physical activity interventions for the prevention of falls. Canadian Journal on Aging, 30(1), 45-55. 


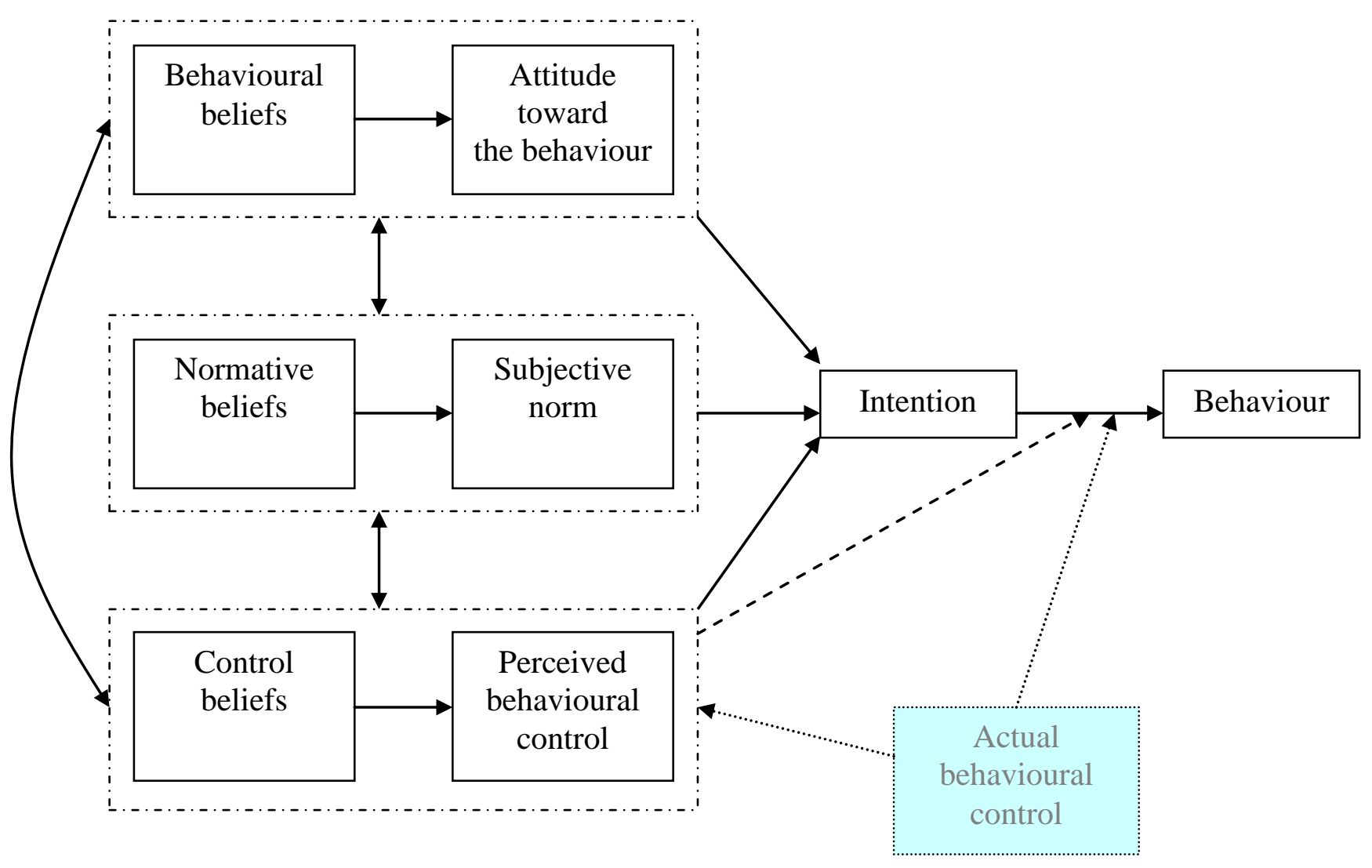

Figure 1: The theory of planned behaviour

Note. From “TPB diagram”, by I. Ajzen, 2006, available online at:

http://people.umass.edu/aizen/tpb.diag.html. Copyright (C 2006 Icek Ajzen. Reprinted with permission.

Nyman, S. (2011). Psychosocial issues in engaging older people with physical activity interventions for the prevention of falls. Canadian Journal on Aging, 30(1), 45-55. 